\title{
8o- Bir uzmanlık alanı olarak tıp çevirisi dersinin çeviri eğitimindeki yeri
}

\section{G. Duygu TÜMER'}

Aslı Selcen ASLAN2

APA: Tümer, G. D.; Aslan, A. S. (2021). Bir uzmanlık alanı olarak tıp çevirisi dersinin çeviri eğitimindeki yeri. RumeliDE Dil ve Edebiyat Araştırmaları Dergisi, (25), 1301-1313. DOI: 10.29000/rumelide.1032601.

\section{$\ddot{O} \mathbf{z}$}

Çeviri sosyal bir iletişim aracı olduğundan toplumsal normlarla yakından ilişkilidir. Normlar toplumsal dinamiklere koşut değişir ve gelişir. Çeviri süreci de içinde yer aldığı mekanizmanın gerekliliklerine göre şekillenir. Temel amacı çeviri edinci kazandırmak olan çeviri eğitiminin kapsamı da toplumsal ve mesleki normlar doğrultusunda belirlenir. Eğitim sürecinde, akademik temelde yürütülen uygulama çalışmalarıyla öğrenciye çeviri olgusunu kuşatan normlara ilişkin farkındalık kazandırılmaya çalışılır. Bu bağlamda, çeviri eğitiminde uygulama dersleri çeviri gerçeklerinin ve sektör dinamiklerinin saydamlaştığı bir ortam sunmaktadır. Müfredatlarda yer alan her bir uzmanlık alanı çevirisi dersi ilgili alana özgü koşulları tanıma ve çeviriye ilişkin yöntem bilgisi ışığında çeviri süreçlerini yönetebilme becerilerine katkı sağlar. Çeviride uzmanlık alanı derslerinden biri olan tıp çevirisi, alanın sunduğu metin türü çeşitliliği sayesinde öğrenciye bilgisini gerçek çeviri işi ortamında sınama firsatı sunar. Bu çalışmanın amacı, çeviriyi kuşatan normları "mesleki normlar" ve "beklenti normları” başlıkları altında inceleyen Andrew Chesterman'ın görüşlerinden yola çıkarak tıp çevirisi dersinin çeviri edincine katkısını değerlendirmektir. Bu doğrultuda, Türkiye'de lisans düzeyinde çeviri eğitimi veren bölümlerin müfredatları incelenerek tıp çevirisi dersinin çeviri eğitimindeki yeri belirlenmiş ve dersin kendine özgü farklılıkları ele alınmıştır. Daha sonra, tıp çevirisi dersinin çeviri edincine katkısı irdelenerek derslerdeki uygulama çalışmalarının planlanmasına yönelik değerlendirmeler yapılmıştır. Bu kapsamda, Christiane Nord’un çeviri amaçlı metin çözümlemesi modelinden yola çıkılarak örnek bir tıp çevirisi süreci ele alınmıştır. Bu yolla, tıp çevirisi dersinin çeviri edinci kazanımındaki işlevsel rolü somutlaştırılmaya çalışılmıştır.

Anahtar kelimeler: Çeviri normları, çeviri eğitimi, çeviride uzmanlık alanları, tıp çevirisi, çeviri edinci

\section{Medical translation course as a special topic in translator training}

\begin{abstract}
Translation, as a utilizer and a tool for communication, is closely related to the norms, and norms change and evolve, following social dynamics. The translation process is transmuted in along with the necessities of the ensuing machinery of the day. Norms also frame translator training whose primary purpose is to equip students with translation competence. In the educational process, we try to develop awareness about the norms surrounding translation phenomenon through the practices designed on academic basis. In this context, applied courses in translator training provide an

Dr. Öğr. Üyesi, Manisa Celal Bayar Üniversitesi, Fen Edebiyat Fakültesi, Mütercim ve Tercümanlık Bölümü (Manisa, Türkiye), duygu.tumer@cbu.edu.tr, ORCID ID: oooo-oool-7865-2349 [Araştırma makalesi, Makale kayıt tarihi: 14.09.2021-kabul tarihi: 20.12.2021; DOI: 10.29000/rumelide.1032601]

2 Dr. Öğr. Üyesi, Manisa Celal Bayar Üniversitesi, Fen Edebiyat Fakültesi, Mütercim ve Tercümanlık Bölümü (Manisa, Türkiye), asli.aslan@cbu.edu.tr, ORCID ID: o0oo-0001-6065-4960
\end{abstract}


environment where translation actuality and industry dynamics become transparent. Each specialized translation course in the curriculum contributes to understanding the conditions specific to the relevant field and managing translation processes considering translation methodology. Medical translation, which is one of the specialization courses in translation, offers students the opportunity to test their knowledge in an authentic translation market environment, thanks to the variety of text types the field offers. This study aims to evaluate the contribution of the medical translation course to translation competence, based on the views of Andrew Chesterman, who examined the norms surrounding translation under the headings of "professional norms" and "expectation norms". In this direction, we examined the departments' curricula that provide translator training at the undergraduate level in Turkey. We determined the place of the medical translation course in translator training and discussed the specific differences among variations. Afterwards, we tried to spot the contribution of the medical translation course to translation competence. We also examined and evaluated possible ways to plan the application in the course. In this context, an exemplary medical translation practice is presented based on Christiane Nord's translational text analysis model. With this practice, we tried to substantiate the functional role of the medical translation course in gaining translation competence.

Keywords: Translation norms, translator training, special topics in translation, medical translation, translation competence

\section{Giriş}

Toplum birbiriyle etkileşim halinde olan bir sistemler bütünüdür. "Toplumsal sistemlerin çoğu -okullar, kiliseler, aileler, ticari kuruluşlar- toplumun alt sistemleridir. Bu alt sistemler toplumsal sistemlerin içinde kendi kendine en çok yeten (ve çevresi üzerinde en çok kontrole sahip olan) bir sistem tarafından kapsanarak onunla ilişkiye girerler ki, bu da toplumdur" (Poloma, 2010: 160). Dolayısıyla, toplumsal değişimler bu bütünü oluşturan bileşenlerin tümünü etkiler.

Toplumsal sistemler yönlendirici ve düzenleyici normlar sayesinde belirli bir düzen içinde işler. Çeviri, toplumsal ihtiyaçların doğurduğu kültürel ve iletişimsel bir olgudur. Dolayısıyla, toplumsal ilişkileri düzenleyen normlar, çeviri sürecinin de belirleyicisi konumundadır. Çeviri normları sosyal etkileşim içinde değerlendirilmelidir ve doğal olarak değişime açıktır (krş. Pym, 1999: 106). Çeviri, farklı alanlarda bir iletişim aracı olduğundan bu normlar ilgili alanların güncel gereksinimleri doğrultusunda şekillenir. Çeviriyi normlar çerçevesinde değerlendiren Andrew Chesterman, çeviri normlarını mesleki ve etik boyutuyla tartışmakta ve çeviriyi yönlendiren normları (a) çeviri sürecine ilişkin "mesleki normlar" ve (b) erek kitle beklentileri doğrultusunda çeviri ürününü ele alan "beklenti normları" olmak üzere iki grupta değerlendirmektedir. Mesleki normlar, "uzman çevirmen" (competent professional translator) davranışlarını belirleyen çeviri sürecine ilişkin alan ve yöntem bilgisini içerir. Öte yandan, beklenti normları erek kitlenin "kalite beklentisini karşlayan erek metinle" (translated texts representing a model of the desired quality) ilgilidir (1993: 8-10).

Bu normlar akademik çeviri eğitiminin çeviri edinci kazandırma amacı çerçevesinde ele alınabilir. Çeviri eğitimi, kuramsal temelde mesleki bilgi ve beceri kazandırmayı hedefler. Genel algının aksine, salt bir uygulama eğitimi değildir. Aynı zamanda, gözlemin, sorgulamanın, neden-sonuç ilişkisi kurmanın ve bunların ışığında üretmenin yolunu açan bilimsel bakışı sunar. Söz konusu bilimsel bakış öğrenciye yalnızca çevirmen olarak değil, mesleki anlamda üstlenebileceği farklı rollerde de katkı sağlar. Bu bakış açısı çeviri eğitiminde uygulama derslerinde somutlaşır. Öğrenci, çeviri uygulamaları aracılığıyla çeviri 
olgusunu kendi bütünlüğü içinde gözlemler, sorgular, betimler ve üretir. Bu sayede, çeviribilimsel kavramların işleyişte nasıl karşıllk bulduğunu da görür.

Çeviri eğitimi müfredatı öğrenciye yukarıda sözü edilen 'çeviri edincini’ kazandırmak üzere kurgulanmalıdır. Okuma edinci, metin çözümleme ve oluşturma edinci, metin türü edinci, kültür edinci ve araştırma edinci gibi birçok alanda kazanılan edinçleri kapsayan bir üst edinç (Eruz, 2008: 53) olarak tanımlanan 'çeviri edinci', akademik çeviri eğitimiyle hedeflenen beceriler bütünü ya da bir üst bakış olarak açıklanabilir. Bu üst bakış, yukarıda sözü edilen ve çeviri eğitiminin sunması gereken bilimsel bakıştır. Çeviri dünyasının kapısını bu üst bakışla aralayan öğrenci, beraberinde gelen yöntem bilgisiyle çeviri süreçlerini yönetebilecektir.

Çeviri edinci, çeviribilim araştırmalarında sıklıkla tartışılan bir konu olmuştur (Pym 2003, Ammann 2008, Eruz 2008, Kussmaul 2011, Baydan 2013, Eser 2015, Durukan, Çelikay 2018). Çeviri edinci kazandırma, birbirini tamamlayan ve geliştiren becerileri öğretme sürecidir. Bu doğrultuda, dersler birbirinin altyapısını oluşturacak ve birbirini besleyecek şekilde planlanır. Çeviri uygulamalarına başlamadan önce verilen Çeviri Amaçlı Metin Çözümlemesi (ÇAMÇ) dersi, metin türü ve metin alt türlerine ilişkin bilgilendirmenin yanında, farklı metin geleneklerini kültürel bağlamlarda değerlendirebilme yetisini geliştirmeye yönelik uygulamaları içerir. İşlevsel bir erek metin oluşturabilmek için gereken adımlar sorgulanarak çeviri süreçlerinde ihtiyaç duyulacak yöntem bilgisini kazanmaya yönelik ilk adımlar atılır. Bu süreç aynı zamanda, çeviri edimine ilişkin mevcut, kulaktan dolma, çoğu zaman eksik hatta yanlış bilgi ve kabullerini yıkarak öğrencilerin çevriyi dilin yanı sıra kültürel ve iletişimsel düzlemlerde değerlendirmesini sağlama sürecidir. ${ }^{3}$ Yine bu amaçla, birinci sınıfta yer alan dil ve kültür odaklı derslerde bu kavramların çeviriyle yakın ilişkisi ele alınır. Sonraki dönemlerde alınan Çeviriye Giriş ve Uzmanlık Alanı Çevirisi dersleri, öğrencilerin yöntem bilgisini kullanmalarına, geliştirmelerine ve içselleştirmelerine olanak sağlayan uygulamaları içerir. Tıp çevirisi de bu derslerden biridir. 4

\section{Çeviri edinci bağlamında tıp çevirisi dersi}

Farklı metin türleri, alt türleri ve gelenekleri ve bunların kültürel bağlamlarına ilişkin farkındalık kazanmaya başlayan öğrenci, metin türü geleneklerinin hukuk, ekonomi, diplomasi, tıp, teknik çeviri, kozmetik gibi uzmanlık alanlarına göre farklılaştı̆̆ı gerçeğiyle karşılaşır. Program kapsamında bulunan farklı alanlara ait her uzmanlık alanı çevirisi dersi, ilgili alanın metin kültürünü ve geleneklerini daha yakından görebilme olană̆ı sunar. Bu durum işlevsel çevirinin önünü açar. Sözü edilen derslerden biri olan Tıp Çevirisi dersinde öğrenciler, bu alandaki alt türleri ve bu türlere özgü metin gelenekleriyle tanışır. Tıp alanındaki metinler kullanmalık metinlerdir. Ancak bu ayrım, alandaki metin türü çeşitliliğinin anlaşılması ve çözümlenmesi için fazla genel olduğundan, metin alt türlerine ait örnekler üzerinden uygulamalar gerçekleştirilir. Örneğin, çevirisi yapılan metin bir hasta kullanma kılavuzu, reçete, epikriz raporu, otopsi raporu, hasta onam formu ya da akademik bir makale olabilir. 5

Türkiye’de İngilizce-Türkçe dil çiftinde eğitim veren lisans düzeyinde 51 bölüm bulunmaktadır. ${ }^{6}$ Tıp çevirisi dersleri 37 bölümün müfredatında 'tıp çevirisi, ileri tıp çevirisi, tıp metinleri çevirisi, tıp çevirisi

\footnotetext{
Tutku Öncü, Akademik Çeviri Eğitimi Bağlamında Çeviri Amaçlı Metin Çözümlemesi Dersi başlıklı yüksek lisans tezinde çeviri eğitiminde ÇAMÇ dersine ilișkin kapsamlı bir araştırma sunmaktadır.

Bu çalışma, Manisa Celal Bayar Üniversitesi İngilizce Mütercim ve Tercümanlık bölümü eğitim planı ve ders içeriklerinden yola çılkılarak hazırlanmıştır. Müfredat kurguları ve ders içerikleri farklı üniversite bölümlerinde değişiklik gösterebilir. Esra Çetintaş Sönmez’in Tıp Metinlerinin Çevirisine İlişkin Yaklaşımlar ve Beklentiler: Bir Olgu Çalışması başlıklı yüksek lisans tezi, konuyla ilgili kapsamlı bir araştırma sunmaktadır. YÖK Atlas 2021
} 
I ve II’ gibi adlarla görülmektedir. 28 bölüm tıp alanında yalnızca bir ders sunmaktadır. 9 bölüm tıp alanında birden fazla ders sunarak öğrenciye seçtiği alandaki bilgi ve uygulama becerisini derinleştirme olanağı sunmaktadır. Tıp çevirisi, 10 bölümde ayrı bir uzmanlık alanı dersi olarak yer almamaktadır. Ancak bu bölümlerin müfredatlarında genel çeviri, uzmanlık alanları, özel alan çevirisi, ihtisas alanları, mesleki çeviri ve toplum çevirmenliği gibi ders içeriklerinde tıp çevirisi uygulamaları yapıldığı belirtilmiştir.

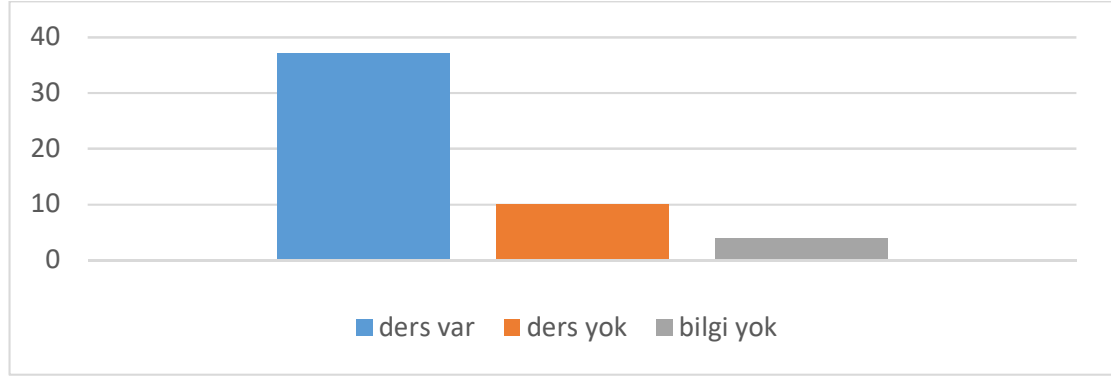

Tablo 1: Müfredatlarda Tıp Çevirisi Dersi Dă̆ılımı

Görüldüğü üzere tıp çevirisi müfredatların çoğunda uzmanlık alanı olarak yer almaktadır. Çevirinin kullanım alanlarının çeşitliliği göz önüne alındığında, tümünün ayrı birer uzmanlık alanı dersi olarak müfredatta bulunması ve düzenli olarak açılması ${ }^{7}$, bölümlerin akademik planlamalarındaki kısıtllıkları nedeniyle mümkün görünmemektedir. Bu kısıtlllıklar içinde ekonomi, hukuk, medya, edebiyat ve tıp gibi belli uzmanlık alanları öncelikli olarak tercih edilmektedir. Söz konusu alanların toplumu oluşturan temel sistemler olduğu düşünüldüğünde, bu sistemlerdeki sözlü ve yazılı iletişim ihtiyacı ön plana çlkmaktadır. ${ }^{8}$ Çeviri eğitiminde bu uzmanlık alanlarında çeviri yapmadan önce, öğrencilerin alana ait temel kavram ve ilkelerle tanıştırılması çeviri uygulamalarını beslemesi açısından önemlidir. Örneğin, hukuk çevirisi dersinden önce hukuk kavramının ne olduğu, kültürlere göre nasıl şekillendiği ve hukuk sistemlerinin nasıl işlediği konularında öğrencinin ön bilgiye sahip olması, çeviri süreçlerini saydamlaştırabilmesinde faydalı olacaktır. Elbette böyle bir giriş dersi, hukukla ilişkili tüm durumların ve tanımların bilgisini sunmayacaktır. Ancak, öğrencinin alanın temel özelliklerine dair kazandığı farkındalık, her durumda yol gösterici olacaktır. Sözü edilen altyapı dersleri zaman zaman bölümler ve fakülteler arası iş birlikleri ile yürütülmektedir. Burada önemli olan, iş birliğinin çeviri eğitimine katkı sağlayacak nitelikte ve sürdürülebilir olmasıdır (Krş. Ertan,2013: 245,258).

Bu noktada tıp alanı diğer alanlardan farklıdır. Bu farklılığın en önemli nedeni tıp alanındaki temel bilgi yoğunluğudur. Parçadan bütüne giden tıp eğitiminde çok sayıda alt dal bulunur. Bu nedenle, tıp eğitimi gerek eğitim süresi gerekse eğitim içeriği açısından diğer lisans programlarından ayrışmaktadır. Eğitim içeriğinde temel tıp bilgisi farklı ders paketleriyle ilk birkaç ylla yayılmaktadır. Örneğin, İstanbul Üniversitesi Tıp Fakültesi eğitim çatısı altında tıbbi bilimlere giriş adıyla birinci sınıfta tıbbi biyoloji, biyofizik, genel biyokimya, genel mikrobiyoloji, genel fizyoloji dersleri bulunmaktadır. 9 Yine Dokuz Eylül Üniversitesi Tıp Fakültesi programında eğitimin ilk üç yllında temel tıp derslerine yer vermektedir. ${ }^{10} \mathrm{Bu}$ nedenle, çeviri eğitiminde diğer uzmanlık alanlarında olduğu gibi temel oluşturacak bir giriş dersi

7 Bazı müfredatlarda çok sayıda uzmanlık alanı seçmeli ders olarak sunulmaktadır. Ancak, alan uzmanı akademik personel eksiği nedeniyle her dersin düzenli olarak açılması gerçekçi görünmemektedir.

8 Sosyal, ekonomik ve teknolojik gelișmeler farklı alanlarda çeviri ihtiyacını doğurabilir ya da var olan ihtiyacı arttırabilir. Son dönemlerde kozmetik çevirisi, spor çevirmenliği, oyun yerelleştirmesi, görsel-işitsel çeviri bunlara örnek olarak verilebilir. Ancak bu durum, yukarıda temel alanlar olarak verilen uzmanlık alanlarının çeviri eğitimindeki öncelikli konumunu değiștirmemektedir.

9 İstanbul Üniversitesi Tıp Fakültesi Mezuniyet Öncesi Eğitim Çatısı, 2021.

$10 \quad$ Dokuz Eylül Üniversitesi Tip Fakültesi Derece Programları, 2021. 
verilememektedir. Bazı temel tıp bilimlerine ilişkin 'genel bilgi' tıp çevirisi dersine dahil edilebilir. Ancak bu durum, öğrencinin temel alan bilgisini edindiği yanılgısını yaratmamalı, tıp öğrencisinin temel derslerini 3-4 yılda tamamlayabildiği hatırlanmalıdır. Bununla birlikte, çevirmenden, tıp uzmanı düzeyinde aktif alan bilgisine sahip olmasını beklemek gerçekçi olmayacaktır. Çevirmenin böyle bir zorunluluğu da yoktur. Çevirmen için önemli olan gerekli bilgiye nasıl ulaşacağını bilmesidir. Bu yönüyle, bilgi edinme ve uygulamanın eşsüremli ilerlediği tıp çevirisi dersi, öğrencinin çeviri edincini birçok yönden besler. Doğru planlanmış uygulamalar özellikle dil edinci, metin edinci ve araştırma edincinin gelişmesine katkı sağlar.

Tıp metinleri teknik yazım ve terimler içeren metinlerdir. Bu özel dil, işlevsellik açısından kullanılan ortama ve kullanıcısına göre değişkenlik gösterir. Alan uzmanlarının profesyonel ortamlarda kullandığı dil, hasta-doktor iletişiminde kullandıkları dilden farklı olabilir. Dolayısıyla, çeviri öncesi süreçte, çeviri amaçlı çzüzmlenmesi yapılırken önce kaynak metnin dil düzleminin saptanması gerekir. Kaynak ve erek metinler arasındaki işlev, metin gelenekleri ve kullanıcı farklılıkları erek metinde kullanılacak dili belirler. Bu durum, kimi zaman dillerarası, kimi zaman da hem dillerarası hem de diliçi çevirinin yapıldığı anlamına gelmektedir. Öğrenci, çeviri uygulamalarını yürütürken, kaynak ve erek dilin farklı bağlamlarda nasıl değişkenlik gösterdiğini görür. Bu uzmanlık dilinin dinamiklerini çözümler. $\mathrm{Bu}$ bağlamda, her bir çeviri uygulaması sonunda, daha sonraki çalışmalarda karşlaşabileceği sorunlar ve çözümler için öngörü oluşturur. Öte yandan, bu deneyim öğrencinin farklı uzmanlık alanlarında yapacağı çevirilerde de yol gösterici olacaktır.

Tıp alanında çok sayıda metin alt türü bulunmaktadır. Bu çeşitlilik ve metinlerin farklı kullanım alanları öğrencinin metin duyarlılı̆̆ını pekiştirecek uygulamalar için zengin malzeme sunar. Öğrenci, uygulamalarda kaynak ve erek kültürde kimi zaman farklılaşan kimi zaman benzeşen metin alt türü geleneklerini gözlemler ve karşılaştırır. Metnin biçimsel ve dilsel özelliklerini ayırt eder ve bunları metin dışı bağlamda değerlendirebilme fırsatı bulur. Bu süreçte, metinle ilişkili alan kültürünü tanırken bu alandaki konu, kavram ve terim bilgisi de gelişmeye başlar.

Bu noktada kilit kavram araştırma becerisidir. "Çevirmen ayrı ayrı kültürlerde doğru yolu bulabilen, ya da doğru yolu bulabilmek için işlevsel kararlar alan ve işlevsel yanttlar alabileceği kimselere doğru sorular sormasını bilen ve bu alanda mümkün olduğunca nesnel davranan kişidir” (Eruz, 2008: 72). Çevirmen 'her şeyi bilen' değil ama sürekli araştıran, ihtiyacı olan her türlü güvenilir bilgiye nereden, nasıl ulaşacağını bilen kişi olmak durumundadır. Dolayısıyla, araştırma becerisi, çeviri edincinin önemli bir parçasıdır. Ayşe Nihal Akbulut, 'Çeviri Eğitiminde Öğrenciye Çeviri Edinci Kazandırma' başlıklı yazısında çeviri eğitiminde öğrencinin okuma alışkanlığı, bilgi birikimi, araştırma ilgisi eksikliklerini gidermeye yönelik uygulamalara yer verilmesinin gerekliliğini belirtmektedir (1995: 13-14). Aynı gereklilik bugünün öğrenci profili açısından güncelliğini korumaktadır. Dahası, teknolojik gelişmeler sayesinde bilgiye daha hızlı ve kolay ulaşılabilmesi, çeviri süreçlerinde nitelikli araştırmanın önemini artırmıştır. Doğru bilgiye en kısa sürede erişen ve bu bilgiyi işlevsel şekilde kullanabilen çevirmen bir taraftan konu ve alan bilgisini desteklerken, bu anlamda mevcut sektör işleyişinin gerektirdiği becerileri de geliştirebilmektedir. Bu nedenle araştırma edinci, çeviri edincinin en kapsayıı bileşenlerinden biri haline gelmiştir. Esra Birkan Baydan'ın ifadesiyle “çevirmen dil, kültür, metin ve herhangi bir uzmanlı alanındaki eksikliklerini ancak araştırma becerisiyle kapatabilir” (2013: 109).

$\mathrm{Bu}$ çerçevede, yukarıda açılanan ve tıp alanını diğer uzmanlık alanlarından farklılaştıran bilgi yoğunluğu, çeviri sürecinde nitelikli araştırmayı ön plana çıkarır. Teknik dil kullanımını içeren tıp çevirisinde çevirmenin mevcut konu ve terminoloji bilgisi, her konu ve metin için yeterli olmayacaktır. 
Bu durumda, koşut metin okumaları, konu ve terim araştırmaları ile çevirmen çeviri süreci içinde alan bilgi açığını kapatır. Öğrenci, tıp çevirisi dersinde nitelikli araştırmaya yönlendirilerek, ihtiyacı olan alan ve terim bilgisine nasıl ulaşacağını, edindiği bilgiyi çeviride etkin şekilde nasıl kullanacağını uygulamalar yoluyla deneyimler.

Tıp çevirisi derslerinin yukarıda tartışılan çerçevede çeviri edincini besleyebilmesi için öncelikle zengin metin çeşitliliği içinden doğru malzemeler seçilmesi önemlidir. Uygulama metinleri:

$>$ güncel,

> çeviri amaçlı çözümleme açısından tartışma ve araştırma malzemesi sunabilecek içerikte,

$>$ öğrencinin düzeyi ve dersin amacına uygun olmalıdır.

Seçilen metinlerin güncel çeviri piyasasında iş hacmini oluşturan metinler ile uyumlu olması, piyasa gerçeklerinin takibi ve sınıf uygulamalarının işlevselliği açısından önemlidir. Gerçek çeviri durumlarına benzer uygulamalarla, öğrenci tıp alanındaki çeviri ihtiyacının ağırlıklı olarak hangi metin alt türlerinde ortaya çıktığı, bu metinlerin özellikleri ve çeviri süreci gereksinimleri konularında bilgisini taze tutabilmelidir. Bunun yanı sıra seçilen metin, 'dil, metin türü-biçem ilişkisi, erek kitle ve çeviri ortamı' sorgulamalarında öğrenciye malzeme sunabilecek ve onu araştırmaya yönlendirecek nitelikte olmalıdır. Bu sayede, öğrenci ÇAMÇ dersinde edindiği bilgiyi bir anlamda sınama ve metin duyarlılığını pekiştirme firsatı bulacaktır.

Öğrencinin düzeyi ve dersin amacı da metin seçiminde belirleyicidir. Örneğin, tıp çevirisi bir müfredatta I ve II olarak iki dönemde yer alıyorsa, birinci derste tıp terimlerine ve diline ilişkin genel bilgi verilerek düşük teknik dil içeren metinlerle çalışılabilir. İkinci derste ise orta ve yüksek teknik dil içeren metin alt türleri seçilebilir.

Öte yandan, dersler gerçek çeviri ortamının bir benzetimi şeklinde planlanmalıdır. Gerçek bir çeviri ortamında olmayan öğrenci, işi talep edeni, kaynak ve erek metinlerin kullanım amaçlarını ve alıcılarını ya da çeviriye özel koşulların olup olmadığını bilemeyecektir. Bu nedenle, uygulamanın ilk adımında çeviri ihtiyacını ve gerekliliklerini tanımlayan bir iş tanımı/bağlam notu (translation brief) verilmesi son derece önemlidir. Bağlam notu, erek metnin işlevini yerine getireceği koşulları tanımlar (Nord, 2008: 46-47). Öğrenci bu doğrultuda işlevsel kararlar alabilir, süreci nasıl yöneteceğini planlayabilir.

Uygulama sonunda geribildirim verilmesi, hedeflenen kazanımların ne derece gerçekleştiğinin görülmesi açısından önemlidir. Öğrenciden istenen çeviri değerlendirmesi, öğrencinin metne yaklaşımı ve bağlam notu doğrultusunda çeviri sürecini nasıl yönettiği hakkında fikir verir. Karşılaştığı sorunlara bulduğu çözümleri, belirsiz ya da eksik bıraktığı noktaları, varsa yanlışları tartışma ortamı yaratır. Bu çerçevede planlanan çalışmalar, öğrencinin çeviriyi kendi gerçekleri ve bütünlüğü içinde algllayabilmesi, bu algı̀ı pekiştirmesi ve içselleştirmesine katkı sağlar.

\section{Tıp çeviri dersinde bir çeviri süreci incelemesi}

Tıp alanı içerdiği bilgi yoğunluğu, özel dil kullanımı, metin alt türü ve kullanım alanlarının çeşitliliği ile çeviri edincini besleyen uygulamalar için zengin bir kaynak sunmaktadır. Öğrenci tıp çevirisi dersinde metin ve dil duyarlılığını pekiştirilebilir. Farklı çeviri kurguları ile her bir çeviri eylemini kendi iç bağlam ve dış bağlamı içinde değerlendirebilme becerisini geliştirebilir. Çeviri edincine yönelik bu kazanımların 
gerçekleşebilmesi için uygun ders materyallerinin seçilmesi ve uygulamaların çeviri gerçekleriyle bağlantılı kurgulanması gerekmektedir.

Öğrenci kaynak metinle karşılaştığı anda zihninde çeviri sürecini kurgulamaya yönelik bir sorgulama başlatmalıdır. Çeviri amaçlı metin çözümlemesi dersinde deneyimlediği iç bağlam ve dış bağlam çözümlemesi aşamaları bu sorgulamayı oluşturur. Christiane Nord’un çeviri amaçlı çözümleme modelinde metin içi ve metin dışı öğeleri saptamaya yönelik belirlediği sorular çözümleme sürecinin temelidir (2005: 41-42). Metin içi öğelere yönelik sorgulama kapsamında konu, içerik, biçim ve biçem özellikleri gibi unsurlar incelenirken metin dışı öğelere yönelik sorgulamada ise metnin göndericisi, amaç, erek kitle, ortam, yer ve zaman, iletişim ihtiyacı gibi unsurlar ele alınır.

Elbette her çeviri uygulamasında bu soruların tümüne yanıt aramaya çalışmak, çevirmen açısından gerçekçi ve işlevsel olmayacaktır. Her metin alt türünün öne çlkan ve çeviri sürecinde yönlendirici olabilecek farklı özellikleri bulunur. Diğer uzmanlık alanı çevirisi derslerinde olduğu gibi tıp çevirisi dersinde de öğrencinin metnin farklılıklarını ve gerekliliklerini fark ederek çeviri kararları alması amaçlanır. Çevirmenin sektör koşullarında bir çeviri işini önce çözümleme sonra çeviriye başlama şeklinde planlaması gerçekçi değildir. Gerçek ortamda bu aşamaların eş zamanlı ilerlediği görülür. Çeviri öğrencisi yöntem bilgisini içselleştirerek çeviri süreçlerini yönetme becerisini deneyim kazandıkça geliştirebilecektir. Ders kapsamında gerçek çeviri durumlarının benzetimi olan her bir çalışma istenilen çevirmen davranışının oluşturulmasına, diğer bir deyişle çeviri edinci kazanmasına katkı sağlayacaktır.

$\mathrm{Bu}$ bölümde, öğrencinin dil ve metin duyarlılı̆̆ını pekiştirmeye, aynı zamanda araştırma edincini geliştirmeye yönelik örnek bir tıp çevirisi süreci ele alınmıştır.

\section{Kaynak metin: ${ }^{11}$}

\begin{tabular}{|l|l|}
\hline \multicolumn{2}{|l|}{ SUNNYLAKE UNIVERSITY HOSPITAL } \\
\hline Patient demographics & \\
\hline Patient name & Anthony Stark \\
\hline Date of birth & 17th May 1968 \\
\hline Patient address & 21 Belview Gardens, LONDON, E21 5HU \\
\hline NHS number & 4567890123 \\
\hline Safety alerts: & $\begin{array}{l}\text { Jehovah's Witness - NO blood products - advance decision documentation } \\
\text { completed }\end{array}$ \\
\hline Risks to self & $\begin{array}{l}\text { Dr S Singh; Manor Farm Road Practice, Manor Farm Road, LONDON, E21 } \\
\text { 7RZ }\end{array}$ \\
\hline GP practice & Smoker \\
\hline GP practice details & \\
\hline Social context & Recently diagnosed RCC following presentation with haematuria \\
\hline Admission details & \\
\hline Reason for admission &
\end{tabular}

${ }_{11} \mathrm{Bu}$ bölümde kullanılan kaynak metin Royal College of Physcians sitesinden alınmıştır. Erişim tarihi: 01.09.2021https://www.rcplondon.ac.uk/guidelines-policy/improving-discharge-summaries-learning-resourcematerials 
1308 / RumeliDE Journal of Language and Literature Studies 2021.25 (December)

Medical translation course as a special topic in translator training / G. D. Tümer; A. S. Aslan (pp. 1301-1313)

\begin{tabular}{|c|c|c|c|c|c|c|c|}
\hline Date/time of admission & \multicolumn{7}{|c|}{ 2nd January 2018; 07:29. } \\
\hline Admission method & \multicolumn{7}{|c|}{ Elective } \\
\hline $\begin{array}{l}\text { Relevant past medical, } \\
\text { surgical and mental health } \\
\text { history }\end{array}$ & \multicolumn{7}{|c|}{$\begin{array}{l}\text { IHD; Hypertension; Aortic Stenosis; COPD; Lumbar disc prolapse with } \\
\text { sciatica; Personality Disorder }\end{array}$} \\
\hline \multicolumn{8}{|l|}{ Diagnoses } \\
\hline Primary diagnosis & \multicolumn{7}{|c|}{ Renal Cell Carcinoma (left kidney) } \\
\hline Secondary diagnoses & \multicolumn{7}{|l|}{ DVT } \\
\hline \multicolumn{8}{|l|}{ Clinical summary } \\
\hline Clinical summary & \multicolumn{7}{|c|}{$\begin{array}{l}\text { Admitted to HDU due to PMH; surgery was uneventfu } \\
\text { left leg } 2 \text { days after surgery and doppler revealed a Lef }\end{array}$} \\
\hline Procedures & \multicolumn{7}{|c|}{ Laparoscopic left nephrectomy: 2nd January 2018.} \\
\hline Investigation results & \multicolumn{7}{|c|}{$\begin{array}{l}\text { eGFR } 40 \text { 11th January 2018; Doppler US Right leg: common femoral, femoral, } \\
\text { popliteal, proximal medial saphenous, and deep femoral veins are patent and } \\
\text { free of thrombus. Deep vein thrombus is identified in the left distal superficial } \\
\text { femoral vein. }\end{array}$} \\
\hline \multicolumn{8}{|l|}{$\begin{array}{l}\text { Discharge details and } \\
\text { Plan }\end{array}$} \\
\hline Date/time of discharge & \multicolumn{7}{|c|}{ 12th January 2018; 14:00. } \\
\hline Discharge destination & \multicolumn{7}{|l|}{ Home } \\
\hline $\begin{array}{l}\text { Plan and requested } \\
\text { actions: }\end{array}$ & \multicolumn{7}{|c|}{$\begin{array}{l}\text { Needs anticoagulation clinic review at local hospital; please complete FP92A } \\
\text { form for a medical exemption certificate }\end{array}$} \\
\hline Information and advice given & \multicolumn{7}{|c|}{ Current smoker - refer to local smoking cessation service. } \\
\hline $\begin{array}{l}\text { Patient and carer concerns, } \\
\text { expectations and wishes }\end{array}$ & \multicolumn{7}{|c|}{$\begin{array}{l}\text { Patient is happy to return to care of his GP but has expressed a wish to stay in } \\
\text { contact with Mr Thomas in Urology during first six months after discharge }\end{array}$} \\
\hline Next appointment details & \multicolumn{7}{|c|}{ Mr. R Thomas Outpatient Department; Suite 5 in 3 weeks. } \\
\hline \multicolumn{8}{|l|}{ Medication } \\
\hline Medication name & Form & Route & $\begin{array}{l}\text { Dose directions } \\
\text { description }\end{array}$ & $\begin{array}{l}\text { Indicatio } \\
\text { n/ } \\
\text { descripti } \\
\text { on of any } \\
\text { amendm } \\
\text { ent }\end{array}$ & $\begin{array}{l}\text { Additi } \\
\text { onal } \\
\text { infor } \\
\text { matio } \\
\mathrm{n} / \\
\text { patien } \\
\mathrm{t} \\
\text { advice }\end{array}$ & $\begin{array}{l}\text { Quant } \\
\text { ity } \\
\text { suppli } \\
\text { ed }\end{array}$ & $\begin{array}{l}\text { Pharma } \\
\text { cy check }\end{array}$ \\
\hline \multicolumn{8}{|l|}{ Status: Added/amended } \\
\hline Codeine Phosphate $30 \mathrm{mg}$ & Tablet & Oral. & $\begin{array}{l}\text { Every 4-6 } \\
\text { hours, PRN }\end{array}$ & Pain & $\begin{array}{l}\text { Max } \\
\text { daily } \\
\text { dose } \\
240 m \\
\text { g in } \\
24 \\
\text { hours }\end{array}$ & & \\
\hline Co-amoxiclav 500/125 & Tablet & Oral. & $\begin{array}{l}3 \text { times a day } \\
(8,14,22)\end{array}$ & IECOPD & & & \\
\hline Enoxaparin $100 \mathrm{mg}$ & Liquid & $\begin{array}{l}\text { Subcut } \\
\text { aneous }\end{array}$ & Once daily (18) & DVT & $\begin{array}{l}\text { Weigh } \\
\text { t } 70 \mathrm{~kg}\end{array}$ & & \\
\hline
\end{tabular}




\begin{tabular}{|c|c|c|c|c|c|c|}
\hline \multicolumn{7}{|l|}{$\begin{array}{l}\text { No changes to patient's } \\
\text { usual medication }\end{array}$} \\
\hline $\begin{array}{l}\text { Allergies and adverse } \\
\text { reactions }\end{array}$ & \multicolumn{6}{|c|}{ Information not available } \\
\hline \multicolumn{7}{|l|}{$\begin{array}{l}\text { Person completing } \\
\text { record }\end{array}$} \\
\hline Dr SR Strachan & $\begin{array}{l}\text { F2 } \\
\text { Keates } \\
\text { ward }\end{array}$ & $\begin{array}{l}\text { Organi } \\
\text { sation }\end{array}$ & $\begin{array}{l}\text { Sunnylake } \\
\text { University } \\
\text { Hospital }\end{array}$ & $\begin{array}{l}\text { 12:01:20 } \\
18: \\
09: 30\end{array}$ & \multicolumn{2}{|c|}{$\begin{array}{l}\text { Checked by Dr } \\
\text { Dash, consultant }\end{array}$} \\
\hline \multicolumn{7}{|c|}{ Distribution list (ce and to include patient) } \\
\hline $\begin{array}{l}\text { Dr S Singh (electronic } \\
\text { transmission) }\end{array}$ & GP & \multicolumn{5}{|c|}{ Manor Farm Road Practice } \\
\hline Anthony Stark (printed copy) & Patient & & & & & \\
\hline \multicolumn{6}{|c|}{$\begin{array}{l}\text { Bağlam Notu: Yukarıda yer alan çıkış özeti (discharge summary), yurt dışında bulunduğu } \\
\text { dönemde hastanede tedavi gören bir hastaya aittir. Hasta Türkiye'de ikamet etmektedir. } \\
\text { Tedavisinin devamı ve takibi için raporun ilgili sağlık birimlerine verilmek üzere Türkçeye çevirisi } \\
\text { yapılacaktır. }\end{array}$} & \\
\hline
\end{tabular}

Bağlam notu kaynak metnin oluştuğu ortam, çevirinin amacı, alıcısı ve kullanılacağı ortam hakkında bilgi vermelidir. Bu bilgi, öğrenciye erek dilde ve kültürde işlerliği olan bir metin üretmesi için gereken kararları almasına yardımcı olacaktır. Bu doğrultuda, öğrenciden kaynak metne özgü özellikleri ayırt ederek çeviri sürecinde kendisini yönlendirecek soruları sorması beklenir. Bu metin özelinde öğrencinin sorgulaması ve araştırması gereken noktalar şöyle sıralanabilir:

Metin alt türüne iliş̧in araştırma: Öğrencinin ilk olarak metnin kaynak kültürde nasıl 'adlandırıldığını' tespit etmesi gerekir. Bu bilgi erek metnin erek kültürde nasıl adlandırılacağının belirleyicisi olacaktır. İki metin arasında adlandırma ve işlev bakımından denklik bulunmayacağı durumlar da karşımıza çıkabilir. Bu durumda iş tanımı/bağlam notu belirleyici olacaktır. Dolayısıyla, ilgili metin alt türünün kaynak kültürdeki adının ve işlevinin bilinmesi yeterli değildir. Bu bilginin çeviri sürecindeki yönlendiriciliğinin bir diğer deyişle, erek metnin erek kültürde nasıl konumlandırılacağının belirlenmesi önemlidir.

Metnin kullanım alanı ve işlevi: Kaynak metnin alan kullanımları, terminoloji kullanımı ve içeriği incelendiğinde metnin bir hasta çlkış özeti olduğu görülecektir. Bu alt tür, alanla ilgili farklı kaynaklarda 'çıkış özeti', 'taburculuk raporu' veya 'epikriz raporu' olarak da görülebilir. Bu belge, hastanın başvuru nedeni, ilk teşhis, uygulanan tetkik ve tedaviler, taburculuk sonrası kullanılacak ilaçlar, diyet, egzersizler ile ilgili bilgileri içeren ve ilgili hekim tarafından çıkışta hasta yakınına verilen bir rapordur. Bu bilgiler hastanın daha sonra alacağı sağllk hizmetlerinde veya sosyal hizmetlerde kendisiyle ilgilenecek kişiyi ve/veya kurumu bilgilendirici ve yönlendirici nitelikte olduğundan son derece önemlidir. Ayrıca hastane çıkışı hastaya refakat edecek kişilerin bilgilendirilmesi açısından da gereklidir. Dolayısıyla, bu alt türün koşut metin araştırması için başvurulacak birincil kaynaklar hastaneler olmalıdır.12 Mevcut sektör koşullarında çevirmen bu çerçevede bir alt tür araştırmasına her zaman vakit ayıramayabilir ancak söz konusu tıp olduğunda alan bilgisi kazanımı çoğu zaman çeviri süreciyle eş zamanlı ilerler. Derste öğrencinin konuya ilişkin araştırmasının tartışılması işlevsel olacaktır. Öğrenci, kaynak kültürde koşut metin araştırmasıyla ilk olarak bu metin alt türüyle ilgili konu bilgisi edinerek içeriğin ne olduğuna 
ilişkin fikir sahibi olur. Metnin amacını ve işlevini çözümleyerek metni kaynak kültürde konumlandırır. Bu noktadan sonra, çeviri kararlarını belirleyen çevirinin bağlamıdır. Bağlam notu değiştiğinde, ortaya çıacak erek metnin işlevi ve metin alt türü de kaynak metinden farklılaşabilir. Öğrencinin bu durumu değerlendirebilmesi, erek metnin içeriğini ve biçimi belirlemesinde yardımcı olacaktır. Bu farkındalık, çeviri kararlarının çıkış noktasıdır. Bu örnekte, metin kaynak ve erek kültürlerde benzer işlevlere sahiptir. Öğrenci bu bilgiye koşut metin tarayarak ulaşabilir.

Metin alt türü gelenekleri: Kaynak metnin biçimsel ve içerik özelliklerinin kaynak kültürde ve kaynak dilde aynı alt türe ait koşut metinler taranarak belirlenmesi gerekir. Mevcut kaynak metnin içerik ve biçim açısından eksik ya da hatalı oluşturulduğu durumlar da bu taramada ortaya çıkacaktır. $\mathrm{Bu}$ aşama, çeviri sürecinde zaman kaybı olarak görülebilir ancak çeviri becerisini geliştirmekte olan öğrencinin uzmanlık alanı bilgisi kazanması açısından gereklidir. Alan uzmanı çevirmen zaman içinde edindiği bilgisi ve deneyimi sayesinde bu aşamada metni her iki kültürde de kolaylıkla konumlandırabilecektir. Seçilen örnekte hasta bilgileri (patient demographics), yatış bilgileri (admission details), teşhis (diagnosis), klinik bulgular (clinical summary), çıkış bilgileri (discharge details and plan), tedavi süreci bilgilendirme (plan and requested actions) ve kullanılacak ilaçlar (medication) ve doktor bilgileri (GP) gibi temel başlıklar bu metin alt türünde bulunması zorunlu olan bilgilerdir. Biçimsel ve içerik olarak kurumdan kuruma farklılık gösterebilir. Örneğin, bu örnekte tablo şeklinde verilen bilgiler bir başka örnekte maddeler halinde ve daha ayrıntılı sıralanabilir.

Öte yandan, erek metnin alt türü ve işlevi benzer olsa da kaynak metnin içeriği dikkatle incelenmeli, farklılıklar var ise, bu farklılıkların aktarılmasına ihtiyaç olup olmadığı tespit edilmelidir. Bu örnekte, kaynak metinde yer alan 'Safety Alerts: Risks to Self' bölümünde 'Jehovah's Witness- NO blood products- advance decision documentation completed' ifadesi bu anlamda dikkat çekicidir. Erek kültürdeki koşut metinlerde bu tür bir başlık yer almamaktadır. Burada, hastanın Yehova Şahidi olduğu için hastaya kan transfüzyonu yapılmayacağı belirtilmiştir. Bağlam notuna dönecek olursak, erek metin geleneklerinde hastaya ait bu kişisel bilginin yazılacağı bir alan bulunmamasına rağmen, buradaki doktorların bu bilgiye sahip olması son derece önemlidir. Bu nedenle, metnin uygun bir yerinde bu açıklamaya yer verilmelidir. Çeviride bu bölüm 'Kişisel Risk Faktörleri: Hasta Yehova Şahididir. Kan transfüzyonu YAPILMAYACAKTIR. Gerekli belgeler hastaya imzalatılmıştır' şeklinde yer alabilir. Yine kaynak metinde 'Patient and carer concerns, expectations and wishes: Patient is happy to return to care of his GP but has expressed a wish to stay in contact with Mr. Thomas in Urology during first six months after discharge' açıklamasında, hastanın taburculuk sonrası durumunu takip edecek doktoruna ilişkin tercihi ve memnuniyetine yer verilmiştir. Erek kültürdeki koşut metinlerde bu bilgiye ait bir başlık bulmamakla birlikte, bilginin tedavinin seyrine etki edecek bir işlevi de yoktur. İhtiyaç olması durumunda kurumlararası iletişim kurulabilecektir. Bu nedenle erek metinde bu bölüme yer verilmeyebilir.

Metnin biçemi: Öğrencinin tıp dilinin özelliklerini göz önünde bulundurarak metnin dilsel özelliklerini çözümlemesi gerekmektedir. Teknik bir yazım gerektiren tıp çevirisinde metin alt türü ve işlevine göre kullanılan dil düzlemi de değişebilir. Öte yandan, kullanılan dil üslup açısından da kültüre göre değişiklik gösterebilir. Çıkış özeti formu bir kültürde daha uzun cümlelerle, açılayıcı ve hastaya yönelik samimi bir tonda oluşturulurken, bir başka kültürde daha kısa ifadelerle ve hastalık bilgisi ön plana çıkarılarak yazılabilir. Bu örnekte, yukarıda metin gelenekleri içinde açıklanan 'Safety Alerts: Risks to Self' ve 'Patient and carer concerns, expectations and wishes' başlıkları, metnin kaynak kültürde 'hasta-dostu' (patient-friendly) bir dil kullanılarak yazıldığını ve hastaya ait kişisel bilgilere daha 
ayrıntılı yer verildiğini göstermektedir. Erek kültürde ise hastalık ve tedavi süreci odaklı, bu anlamda daha mekanik bir anlatım tercih edilmektedir.

Terminoloji: Tıp çevirisinde özellikle erek dilde yapılan koşut metin araştırması terimlerin erek dilde ilgili uzmanlık alanındaki yerleşik kullanımlarına ilişkin bilgi sağlar. Bir terimin erek dilde birden fazla karşılığı olabilir. Yerleşik terim kullanımları, anabilim dalları ve sağlık kuruluşları özelinde farklılaşabildiği gibi çevirinin amacı ve alıcısı da terim kullanımlarında belirleyici rol oynayabilir. $\mathrm{Bu}$ noktada, farklı çeviri tercihlerinin ders ortamında tartışılması çeviri sürecinde bağlam notunun belirleyici etkisinin görülmesini sağlar. Örneğin, erek dilde yapılacak koşut metin taramalarında deri altı enjeksiyon uygulaması için kullanılan 'subcutaneous' teriminin 'subkutan' olarak kullanıldığı görülecektir. Ancak, farklı bir bağlamda, farklı bir kullanıcı için söz konusu terim için 'deri altı' ifadesi tercih edilebilir. Bir diğer örnekte de 'Lumbar disc prolapse' ifadesi için lombar disk herniasyonu, prolapsı ya da disk sarkması ifadeleri duruma göre tercih edilebilir.

Erek metnin kullanıcısı: Erek metnin içeriğini, dil kullanımını ve biçimsel özelliklerini belirleyecek olan bilgi temelde erek kitledir. Müşterinin ihtiyacını metin alt türü geleneklerinin dışına çıkan bir metin de karşılayabilir ya da müşteriden bu yönde bir talep gelebilir. Ancak, müşterinin çeviride alan uzmanı olmadığı göz önünde bulundurularak erek metnin işlevini engellemeyecek bir metin oluşturmak çevirmenin sorumluluğudur. Bu örnekte, metnin birden fazla kullanıcısı bulunmaktadır. Daha önce sözü edildiği gibi, çıkış özeti, hastayı, hastanın refakatçisini ve sonrasında tedavisini takip edecek olan doktoru veya sağlık kuruluşunu bilgilendirmek üzere verilir. Kaynak kültürde bazı formlarda bu çoklu işlev göz önünde bulundurularak rapora 'information for patient and carer' şeklinde bir bölüm bulunmaktadır. Bu bölümde bilgiler hasta ve hasta yakının anlayacağı açıklıkta yer almaktadır. Erek kültürde ise çıkış özetlerinde böyle bir fark gözetilmediği görülmektedir.

Yukarıdaki açıklamalar ışı̆̆ında, çeviri sürecinin bağlam notu doğrultusunda ilerlediği görülmektedir. Erek kültürdeki koşut metinlerde biçim, kullanılan dil ve içerik özellikleri tarandıktan sonra çeviri ihtiyacına göre bu bilgiler elenerek en işlevsel olanlar seçilir. Ders süreci, öğrencilerin eleme ve seçme süreçlerindeki farklılıkları ve kararlarının arka planını açıklamalarıyla ilerler. Bu tartışmalar, zihinsel süreçlerin somutlaşmasını sağlar. Öğrenci farklı çeviri tercihlerini ve araştırma kaynaklarını görerek öz değerlendirme yapma firsatı bulur. Öte yandan, bu tür uygulamalarda yapılan araştırma ve okumalar, konu çeşitliliği ve bilgi yoğunluğu fazla olan tıp alanına ilişkin konu ve terim bilgisini de besler. Tip çevirisinde çevirmenden beklenen uzmanlık alanı bilgisi (ikinci uzmanlık alanı tıp değilse) ancak bu sayede gelişebilir.

\section{Sonuç}

Toplumsal yaşamı düzenleyen normlar birbiriyle etkileşim halindedir ve bir alandaki değişim diğerlerini de etkiler. Eğitim sistemi bu ilişkiler bütünü içinde yer almaktadır. Dolayısıyla, eğitim içerikleri sözü edilen normlara uyum sağlayacak şekilde oluşturulur. Toplumsal, kültürel ve iletişimsel bir olgu olan çeviriye ilişkin akademik eğitim, toplumsal normlardan kopuk düşünülmemelidir. Çeviri edimini kuşatan normlar, mesleğe ilişkin nitelikleri ve çeviri ihtiyacını karşılayacak ürünün özelliklerini etkiler. Çeviri eğitiminde yer alan çeviri uygulamaları sözü edilen normların oluşturduğu beklentiyi karşılayacak nitelikte olmalıdır. Bu anlamda, uzmanlık alanı çevirisi derslerindeki uygulamaların işlevsel bir planlamayla çeviri edincini desteklediği görülmektedir. Tıp alanına özgü dil kullanımı, metin çeşitliliği ve yoğun alan ve terim bilgisi, uzmanlık alanı çevirisi dersleri arasında tıp çevirisini önemli bir konuma taşımaktadır. Çeviri eğitimi veren bölümlerin çoğunun müfredatında tıp çevirisinin yer alması bu 
durumun bir göstergesidir. Öğrenciler, bu ders kapsamında, çeviri amaçlı metin çözümlemesi dersinde tanıştığı dil ve metin duyarlılığını ne kadar içselleştirebildiğini, araştırma becerisini etkin şekilde kullanıp kullanamadığını uygulama ortamında görür. Çalışmalarda, farklı bağlamlarda çeviri sürecinin nasıl değişebileceği gösterilir. Öğrenciler, metin alt türü özelliklerinin, dil kullanımının, amaç ve işlevin kaynak ve erek kültürlerde her zaman örtüşmediğini gözlemler.

Ders kapsamındaki uygulamalarda alana ilişkin yöntem bilgisi içselleştirilir. Böylelikle, mesleki normlar içinde tanımlanan çeviri becerilerine katkı sağlanır. Öte yandan, erek kitle beklentileri doğrultusunda alınan çeviri kararları, öğrencilerin beklenti normları ile açıklanan nitelikte erek ürün yaratma becerilerini de geliştirir. Sonuç olarak tıp çevirisi dersinin, sözü edilen iki norm kapsamında belirtilen çevirmen ve ürün niteliklerinin kazandırılmasına katkı sağladığı görülmektedir.

\section{Kaynakça}

Akbulut, A. N. (1995). Çeviri Eğitiminde Öğrenciye Çeviri Edinci Kazandırma: Çevirmen Kararları ve Dayanakları. (I. Bengi-Öner, Dü.) Çeviribilim 1, 13-24.

Ammann, M. (2008). Akademik Çeviri Eğitimine Giriş. (E. D. Ekeman, Çev.) İstanbul: Multilingual.

Birkan Baydan, E (2016). Çeviri Eğitiminde Çeviri/Çevirmenlik Edinci: Problem Çözme ve Karar Verme Konusunda Bir Farkındalık Uygulaması. İstanbul Üniversitesi Çeviribilim Dergisi, 4(7), 103-125.

Chesterman, A. (1993). From 'Is' to 'Ought': Laws, Norms and Strategies. Target, 5(1), 1-20.

Çetintaş Sönmez, E. (2011, Haziran). Tıp Metinlerinin Çevirisine İlişkin Yaklaşımlar ve Beklentiler: Bir Olgu Çalışması. Yüksek Lisans Tezi. Dokuz Eylül Üniversitesi Tıp Fakültesi. (2021, 08 24).

Derece Programları: https://debis.deu.edu.tr/ders-katalog/2015-2016/tr/bolum_1081_tr.html adresinden alınd

Durukan, E., \& Çelikay, M. (2018). Çeviri Edinci Kavramına Yönelik Kapsayıcı Bir Tanım Önerisi. Turkish Studies, 13(12), 161-176.

Ertan, E. (2013). Uzmanlık Alanları Çevirilerinin Tarihsel Süreci Eğitimi Önemi ve Çeviri Uygulamalarındaki Konumu. İstanbul: Efe Akademi Yayınları.

Eser, O. (2015). Çeviribilimde Edinç Araştırmaları. Ankara: Anı Yayıncılık.

İstanbul Üniversitesi Tıp Fakültesi . (2021, 08 24). Mezuniyet Öncesi Ĕ̆tim Çatısı: https://istanbultip.istanbul.edu.tr/tr/content/mezuniyet-oncesi/egitim-catisi adresinden alındı

Kahramanmaraş Sütçü İmam Üniversitesi Sağllk ve Araştırma Hastanesi. (2021, 08 25). https://hastane.ksu.edu.tr/Default.aspx?SId=19183 adresinden alındı

Kussmaul, P. (2011). Components of Translation Competence. Turgay Kurultay'a Bir Armağan. Çevbiribilimden Kestiler (s. 245-259). içinde İstanbul: Multilingual.

Nord, C. (2005). Text Analysis in Translation. Theory, Methodology, and Didactic Application of a Model for Translation-Oriented Text Analysis (2 b.). Amsterdam-New York: Rodopi.

Nord, C. (2008). Defining translation functions. The translation brief as a guideline for the trainee translation. Ilha do Desterro, 41-55.

Ordu Üniversitesi Eğitim ve Araştırma Hastanesi. (2021, 09 02). https://ordueah.saglik.gov.tr/TR,292600/hasta-yatis-ve-taburculuk-islemleri.html adresinden alındı

Öncü, T. (2016). Akademik Çeviri Eğitimi Bağlamında Çeviri Amaçlı Metin Çözümlemesi Dersi. Yüksek Lisans Tezi.

Polama, M. M. (2010). Çağdaş Sosyoloji Kuramları (1. baskı: 1993 b.). (H. Erbaş, Çev.) Ankara: Gündoğan Yayınları. 
Pym, A. (1999). Okay, So How Are Translation Norms Negotiated? A Question for Gideon Toury and Theo Hermans. C. Schäffner (Dü.) içinde, Translation and Norms (s. 106). Multilingual Matters.

Pym, A. (2003). in an Electronic Age. In Defence of a Minimalist Approach. Meta, 48(4), 481-497. Redifining Translation Competence

Yök Atlas. (2021, 08 15). Yök Lisans Atlası: https://yokatlas.yok.gov.tr/lisans-anasayfa.php adresinden alınd 